\title{
The Question of Short Lower Limb and Long Lower in Manual Therapy: An Overview
}

\author{
Luca Collebruscoํ, Giovanna Censi ${ }^{2}$, Paola Casoli ${ }^{3}$ \\ ${ }^{1}$ Rehabilitation Unit, National Health Service of Umbria, Perugia, Italy \\ ${ }^{2}$ INRCA, University Polytechnic of Marche, Ancona, Italy \\ ${ }^{3}$ Neurorehabilitation Clinic, University Polytechnic of Marche, Ancona, Italy \\ Email: luca.collebrusco@unipg.it
}

How to cite this paper: Collebrusco, L., Censi, G. and Casoli, P. (2020) The Question of Short Lower Limb and Long Lower in Manual Therapy: An Overview. Open Journal of Therapy and Rehabilitation, 8, 143-152.

https://doi.org/10.4236/ojtr.2020.84013

Received: September 6, 2020

Accepted: October 11, 2020

Published: October 14, 2020

Copyright $\odot 2020$ by author(s) and Scientific Research Publishing Inc. This work is licensed under the Creative Commons Attribution International License (CC BY 4.0).

http://creativecommons.org/licenses/by/4.0/

\begin{abstract}
The purpose of this paper is to review relevant literature concerning limb length inequalities in adults and to make recommendations for assessment and intervention based on the literature and our own clinical experience. The research was carried out on PUB MED, Non-English articles and duplicates in the databases were not included. Limb length inequality and common classification criteria are defined and etiological factors are present. Common methods of detecting limb length inequality include model manual technics. This work has the purpose of describing a well standardized therapeutic in the form of practical guidance. The approach we describe provides standardized model evaluation for leg lower limb in order to be used in rehabilitation clinic.
\end{abstract}

\section{Keywords}

Leg Length Discrepancy, Leg Length Inequality, Diagnostic Techniques and Procedures

\section{Introduction}

Leg length discrepancy (LLD) has been found to be a significant factor influencing several pathological and physiological conditions, which affect function and quality of life [1] [2]. LLD occurs in about $40 \%-70 \%$ of the population. Most have a leg length difference smaller than $20 \mathrm{~mm}$. The past several decades, limb length inequality has been the topic of a great deal of disagreement among clinical investigators and researchers. The existence of limb length inequality is not in doubt. Little agreement exists, however, regarding the degree of limb length inequality that is considered clinically significant [3]. Several classification systems or categories of limb length inequality have been propos. The most com- 
mon classification scheme for limb length inequality identifies two types: anatomical and functional [4]. The therapist effects specific manual sequences for differential limb length discrepancy. The LLD not only restrict bony mobility, but also compress neurovascular and fascial structures and disturb their functions. The assessment LLD can be defined as an evaluative model for the management of patients with musculoskeletal disorders according to International Classification of Disease (ICD), ICD-10-CM, M 99.09 in somatic dysfunction (SD), which implies that a dysfunctional and segmental event of a part of the body can give a remote repercussion in another regional complex [5]. It is not easy to establish in clinical practice if a LLD is structural (SLLD) or functional (FLLD), despite the theoretical distinction. A SLLD is considered an actual shortening of the skeletal system between the hip of and ankle joint, the anatomical difference between the lengths of the two limbs between the proximal edge of the femoral head to the distal edge of the tibia, which can be congenital or acquired [6]. A FLLD can occur as result of joints misalignment of lower limbs and rotated pelvis [5] [7] [8] can cause alteration of lower limb mechanics, such as joint contracture, static or dynamic mechanical axis misalignment, muscle weakness or shortening. The therapist selects sequence a group manual tests for classification lower limbs discrepancy. The techniques will also be classified according to the type of manoeuvres described in the literature and will be explained in detail [9]. The present paper defines a simple assessment plan for therapists, which is design for LLD in the context of SD assessment. We provide an overview of its management according to the current evidence-based literature. A number of different assessment tools and methods are proposed.

\section{Criteria and Strategies Research Assessment LLD}

The assessment of the limbs must include inspection of the patient, gait analysis, and palpation and movement of both limbs [10] [11] [12] [13]. Early recognition of leg length discrepancy is essential for correct homeostasis and quality of life the patient [14] [15] [16]. A brief description of each available method used to determine LLD, will be illustrated below (Figure 1).

\section{Methods used for Assessing LLD in the Practical}

Direct assessment of apparent LLD during physical examination is performed with the patient supine and involves measuring from the anterior superior iliac spines (ASIS) to the medial malleolus (Figure 2(A)) [17], (true leg length discrepancy with oblique pelvis). Always with the patient supine, the examiner uses a tape measure to assess the distance between the umbilicus and the medial malleolus (Figure 2(B)). Leg length assessments or the prone check (Figure 3), the participants approached the foot of the table and knelt on the foot of the table. The participants then lay prone, using their arms to pull the body cephalad until the ankles were at the foot of the table, attempting to remove any table positioning artefacts. For the supine check (Figure 4), the participants approached the foot 


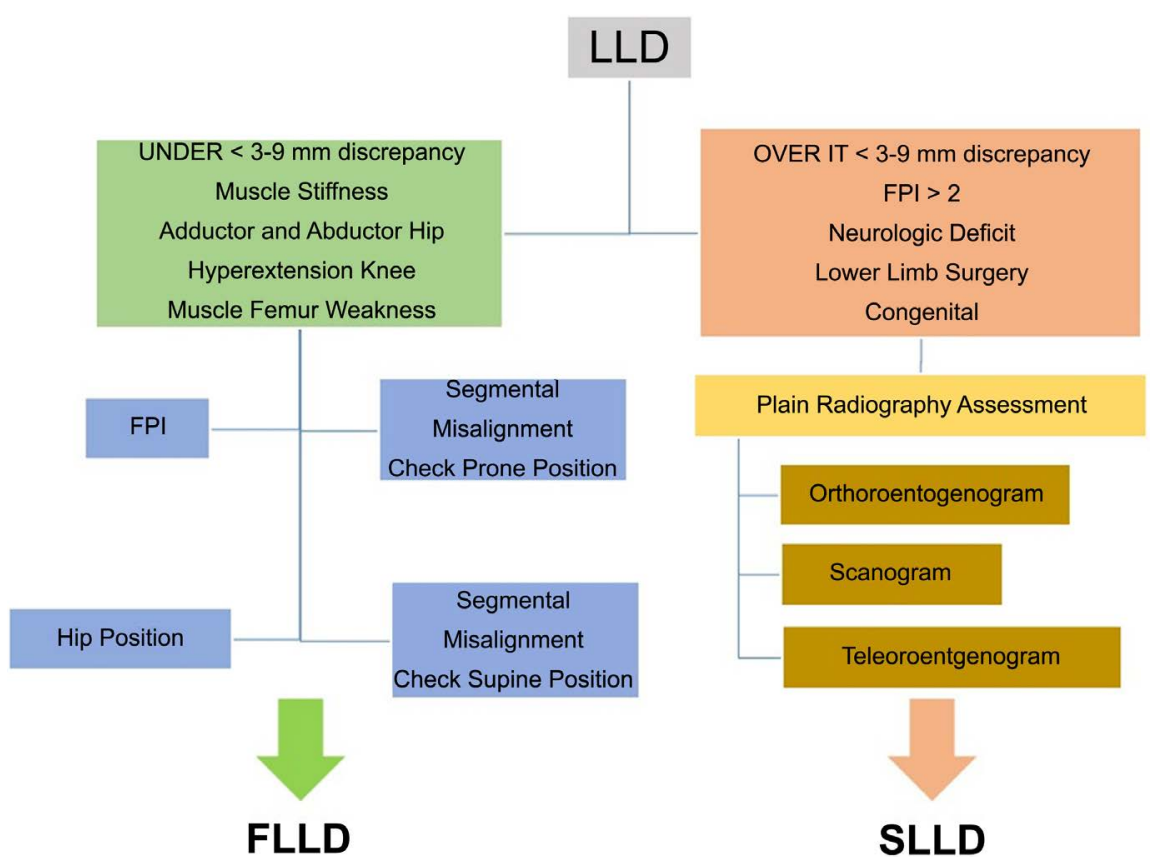

Figure 1. Flowchart: leg length discrepancy assessment. Legend: Leg Length Discrepancy (LLD), Foot Postural Index (FPI), Structural Leg Length Discrepancy (SLLD), Functional Leg Length Discrepancy (FLLD).

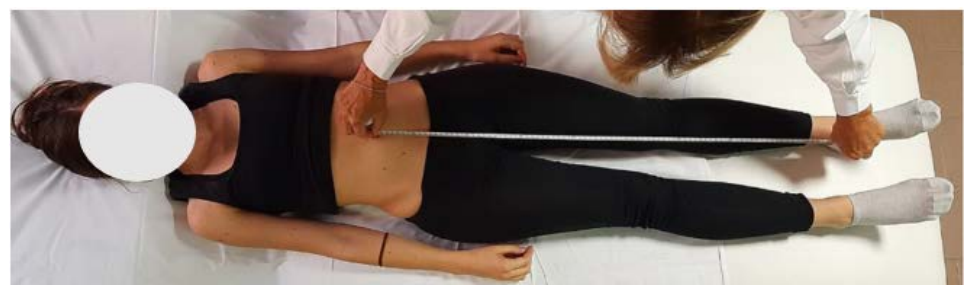

(A)

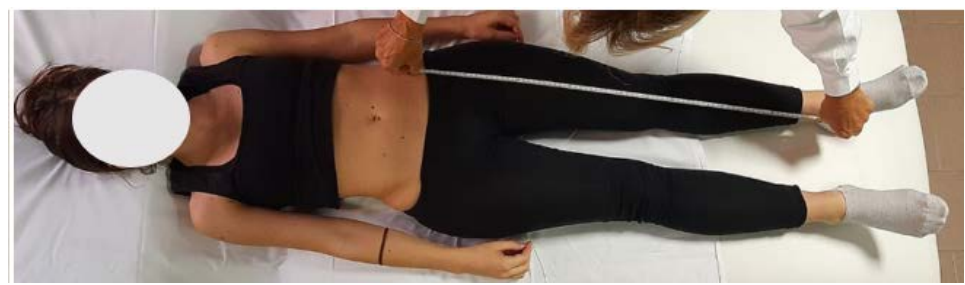

(B)

Figure 2. Measure leg length. Screen for LLD: (A) With the patient supine, the examiner uses a tape measure to assess the distance between the anterior superior iliac spines and the medial malleolus, (B) With the patient supine, the examiner uses a tape measure to assess the distance between the umbilicus and the medial malleolus.

of the table and sat down at the foot of the table. They then used their arms to pull their seated bodies toward the head of the table until their ankles cleared the foot of the table, attempting to remove any table positioning artefacts. The examiners were required to judge either the left or the right leg short [18]. Assessment for leg length inequality in the prone position may detect consequences of pelvic torsion, whereas supine assessment may detect consequences of upper 


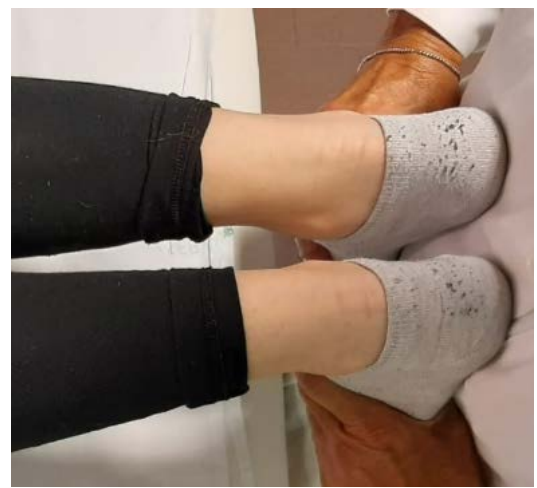

Figure 3. Prone leg checking. Manoeuvre: The patient is in a prone position with their legs stretched out; therapist performed an ankle dorsiflexion, compare lengths of internal malleolus.

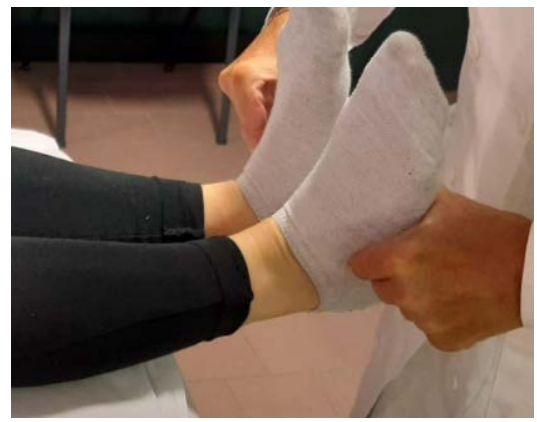

Figure 4. Supine leg checking. Manoeuvre: The patient is in a supine position with their legs stretched out; therapist performed an ankle dorsiflexion, compare lengths of internal malleolus.

cervical segmental misalignment [18]. Abnormal pronation patterns we quantified using the Foot Posture Index (FPI) in a modified stance position: arms extended, forward lean against the wall, knees sufficiently bent to load the forefoot, score FPI $<2$ from abnormal pronation for misalignment leg length (Figure 5).

The relative position of the posterior superior iliac spines. With the subject standing relaxed, unshod, and with vision directed forward, the posterior superior iliac spines (PSIS) were located by palpation (Figure 6).

The dysfunction pelvic model is delineated as follows: Abnormal pronation pulls the innominate bones anteriorly; anterior rotation of the innominate bones pulls the acetabula, and the femoral heads, cephalad (upward) and posteriorly; and this, in turn, hyperextends the knees and functionally shortens the legs, with the shortest leg associated with the more pronated foot. The supine prone and standing positions may have different impacts on functional leg length inequality.

We can have two answers to the evaluation:

- FLLD: leg length $<3$ - $9 \mathrm{~mm}$, and pronated feet in a modified stance position FPI score $<2$ [19].

- SLLD: leg length $>9 \mathrm{~mm}$, and pronated feet in a modified stance position FPI score $>2$, (PFI) [19]. 


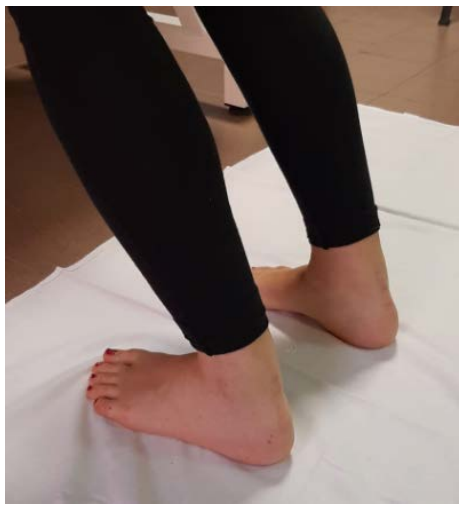

(A)

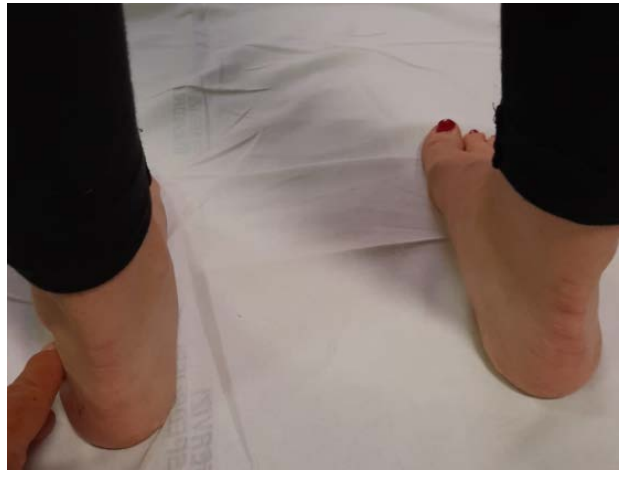

(B)

Figure 5. Foot postural index (FPI) evaluation. Manoeuvre: (A) The patient stands in a forward lean position with the body's weight over the inner longitudinal arch. (B) The feet are placed by the subject in a comfortable position as close to their natural base and angle of gait as possible.

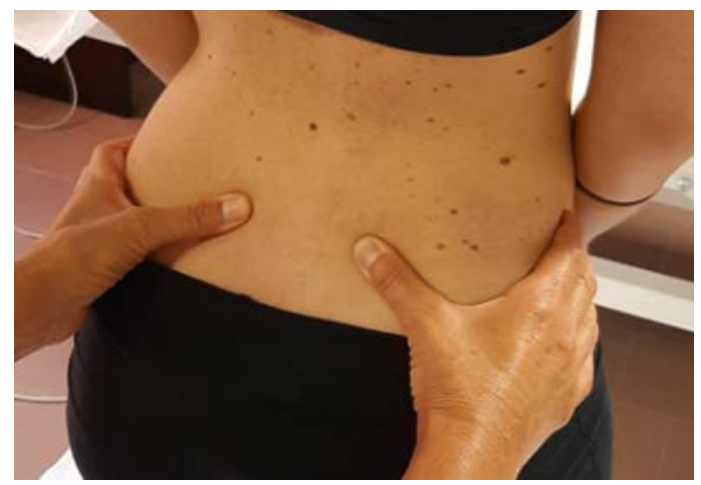

Figure 6. Palpation of the Posterior Superior Iliac Spine (PSIS).

In SLLD assessment associated may occur visual impairments, inner ear or balance problems, history of trauma to the hip or lower limb, history of surgery of the lower limb, and history of neurologic deficits that affect foot or hip posture. Imaging methods are included in the evaluation of the SLLD, there is general agreement that radiographs are more accurate and reliable than clinical methods for assessing LLD [20]. Although various imaging techniques have been used to evaluate leg-length inequality, plain Radiography remains the gold stan- 
dard [21], standing anterior-posterior radiograph of the lower extremity (modified teleoroentgenogram).

\section{Discussion}

Leg length discrepancy can be structural or functional; both can cause postural compensations that contribute to pain and/or functional compromise. However, there are potential sources of error with tape measurements related to differences in leg circumference, angular deformities, and difficulty in accurately palpating bony prominences as well as joint contractures [22]. Positive correlation exists between the most pronated foot and the shortest leg [22] [23] [24]. LLD may result in degenerative changes of the lumbar spine, altered gait mechanics, and low back pain [25]. Some studies suggest that LLD is associated with low back pain [26]. LLD causes pelvic obliquity in the frontal plane [27]. The length discrepancy of lower limbs leads to posture deformation, gait asymmetry, low back pain, discopathy as well as gonarthrosis, coxarthrosis and hip flexion contracture on the side of the longer extremity or ankle joint contracture in the equine position on the side of the shorter extremity, with lumbar convexity towards the short lower limb [27]. The discrepancies of 5 to $25 \mathrm{~mm}$ are not necessarily a functional detriment to marathon runners, and no consistent benefits could be attributed to the use of a lift [28].

Analysis of the data, using $10 \mathrm{~mm}$ as the threshold of difference, reveals high levels correlation and no significant difference between measurements obtained from standing and supine radiographs. A weak correlation and statistical difference existed between each set of radiographic measurements and physical examination measurements [29]. A radiographic investigation for leg length inequality should be considerd as the cause of low back pain, an x-ray of the standing posture of the entire pelvis and lumbar spine are essential to assess existing pelvic tilt and scoliosis [30]. There are large differences between prone and radiographic measurements in some cases indicating that caution should be exercised when using the prone-only method to estimate leg length discrepancy [31]. There is an association between mild leg length inequality and LBP [32]. Asymmetry, including compensatory scoliosis with leg length difference, there was no difference in predisposition in trunk flexion fatigue [33]. Precise determination of LLD is an important problem. The assessment LLD is associated with numerous postural alignment challenges presented in algorithm. The work is the result of the literature review includes both review articles and clinical trial articles grouped in Table 1 who based on sample size, average age of patients and population.

To provide an evidence-based instrument to aid the clinician in a practical approach to evaluation and treatment in manual therapy, previous clinical methods have limited reliability and depending on them for determining the need for intervention, might be misleading. There are still differences of opinions as to the role LLD plays in musculoskeletal disorders. Some investigators accept as 
Table 1. Studies using reliable means of determining magnitude of anatomic leg-length inequality.

\begin{tabular}{|c|c|c|c|}
\hline STUDY & SAMPLE SIZE & MIDDLE AGE & POPOLATION \\
\hline Gross R. et al. 1983 & 35 & 35 & MARATHON RUNNERS \\
\hline Venn E.K.et al. 1983 & 60 & & RANDOMLY CHOSEN PATIENTS \\
\hline Cleveland R.H. et al. 1998 & $\begin{array}{c}10 \\
6 \text { men - } 4 \text { women }\end{array}$ & 41 & LOW BACK PAIN PATIENTS \\
\hline Hoikka V. et al. 1989 & $\begin{array}{c}100 \\
53 \text { men }-47 \text { women }\end{array}$ & 40 & CHRONIC LOW BACK PAIN \\
\hline BEATTLE P. et al. 1990 & $\begin{array}{c}19 \\
9 \text { men - } 10 \text { women }\end{array}$ & 30 & CLINICAL SUBJECTS \\
\hline SOUKKA A. et al. 1991 & 247 & 44 & LOW BAKC PAIN \\
\hline RHODES D.W. et al. 1995 & 50 & & LOW BACK PAIN \\
\hline MINCER et al. 1997 & $\begin{array}{c}54 \\
10 \text { men - } 44 \text { women }\end{array}$ & & VOLUNTEERS \\
\hline HAVRAN M. et al. 1998 & 1 men & 84 & CHRONIC LOW BACK PAIN \\
\hline HYMAN A. et al. 2006 & 8 men & & LLD and SUBMALLEOLAR DEFORMITY \\
\hline BRIAN A. et al. 2006 & 100 & 48 & LLD and SCOLIOSIS and LOW BACK PAIN \\
\hline RANNISTO S. et al. 2015 & $\begin{array}{c}114 \\
88 \text { men }-26 \text { women }\end{array}$ & & LLD and LOW BACK PAIN \\
\hline JAN W. et al. 2010 & $\begin{array}{c}369 \\
160 \text { men - } 209 \text { women }\end{array}$ & 10 & LLD and PELVIC OBLIQUITY and SCOLIOSIS \\
\hline
\end{tabular}

much as $20-30 \mathrm{~mm}$, while others define a significant discrepancy of $3-5 \mathrm{~mm}$ [6] [26] [34]. We believe that physiotherapist should not depend solely on tape measure measurements for clinical decisions. The assessment LLD can aid in recognizing the contribution of segmental alignment and joint movement on effective leg length and accordingly, decide if there is a need for intervention manual therapy [34].

\section{Conclusions}

To promote a patient centred approach, providers should consider evaluating for LLD in somatic dysfunction. A benefit of the screening examination is that the patient is examined in standing, sitting, supine, and prone. This permits assessment in both weight bearing and non-weight-bearing positions.

Each component of the lower extremity is systematically examined to determine possible contributing factors to limb length inequality [35]. The question of whether to treat individuals with LLD should be taken on a case-to-case basis. The Knowledge for assessment FLLS and SLLD may assist clinicians in understanding tissue stress patterns that are associated with skeletal misalignments. This knowledge is essential in making decisions regarding activity modification, manual therapy and postural therapy. The detection of LLD should base on the integration of the static and dynamic assessment, dynamic leg length during the gait cycle, imaging if available. The combination of these assessments can provide a more precise measurement for evaluation LLD. By adding the FLLD and 
SLLD concept in manual therapy, it would make the clinical faster and more standardized.

\section{Conflicts of Interest}

The authors declare no conflicts of interest regarding the publication of this paper.

\section{References}

[1] Iversen, M.D., et al. (2011) Influence of Self-Reported Limb Length Discrepancy on Function and Satisfaction 6 Years after Total Hip Replacement. Journal of Geriatric Physical Therapy, 34, 148-152. https://doi.org/10.1519/JPT.0b013e31820e16dc

[2] Vitale, M.A., Choe, J.C. and Sesko, A.M. (2006) The Effect of Limb Length Discrepancy on Health-Related Quality of Life: Is the " $2 \mathrm{~cm}$ Rule" Appropriate? Journal of Pediatric Orthopaedics, 15, 1-5.

[3] Brady, R.J., Dean, J.B., Skinner, M.T. and Gross, M.T. (2003) Limb Length Inequality: Clinical Implications for Assessment and Intervention. Journal of Orthopaedic \& Sports Physical Therapy, 33, 221-234. https://doi.org/10.2519/jospt.2003.33.5.221

[4] Danbert, R.J., et al. (2008) Clinical Assessment and Treatment of Leg Length Inequalities. Journal of Manipulative and Physiological Therapeutics, 11, 290-295.

[5] Collebrusco, L., Lombardini, R. and Censi, G. (2016) Regional Interdependence: A Model That Needs to Be Integrated in the Functional Evaluation and Physiotherapy Treatment-Part 1. Open Journal of Therapy and Rehabilitation, 4, 117-124. https://doi.org/10.4236/ojtr.2016.43010

[6] Khamis, S. and Carmeli, E. (2017) A New Concept for Measuring Leg Length Discrepancy. Journal of Orthopaedics, 14, 276-280. https://doi.org/10.1016/j.jor.2017.03.008

[7] Friberg, O., Nurminen, M., Korhonen, K., Soininen, E. and Mänttäri, T. (1988) Accuracy and Precision of Clinical Estimation of Leg Lenght Inequality and Lumbar Scoliosis: Comparision of Clinical and Radiological Measurements. International Disability Studies, 10, 49-53. https://doi.org/10.3109/09638288809164098

[8] Collebrusco, L., Lombardini, R. and Censi, G. (2017) Regional Interdependence: A Practical Guidance in Rehabilitation Clinic-Part 2. Open Journal of Therapy and Rehabilitation, 5, 11-28. https://doi.org/10.4236/ojtr.2017.51002

[9] Coffey, D., et al., (2017) Leg Length Discrepancy: The Importance of a Complete History and Examination. BMJ Case Reports, 2017, Article ID: 220985.

https://doi.org/10.1136/bcr-2017-220985

[10] Bhave, A., et al., (1999) Improvement in Gait Parameters after Lengthening for the Treatment of Limb-Length Discrepancy. The Journal of Bone and Joint Surgery, 81, 529-534. https://doi.org/10.2106/00004623-199904000-00010

[11] Aguilar, E.G., et al., (2017) Distance between the Malleoli and the Ground. Journal of the American Podiatric Medical Association, 107, 112-118. https://doi.org/10.7547/15-013

[12] Woerman, A.L., et al. (1984) Leg Length Discrepancy Assessment: Accuracy and Precision in Five Clinical Method Evaluation. Journal of Orthopaedic \& Sports Physical Therapy, 5, 230-239. https://doi.org/10.2519/jospt.1984.5.5.230

[13] Petrone, M.R., et al. (2003) The Accuracy of the Palpation Meter (PALM) for Measuring Pelvic Crest Height Difference and Leg Length Discrepancy. Journal of Or- 
thopaedic \& Sports Physical Therapy, 33, 319-325. https://doi.org/10.2519/jospt.2003.33.6.319

[14] Selye, H. (1956) The Stress of Life. Mcgraw-Hill, New York.

[15] Mueller, M.J. and Maluf, K.S. (2002) Tissue Adaptation to Physical Stress: A Proposed "Physical Stress Theory" to Guide Physical Therapist Practice, Education, and Research. Physical Therapy, 82, 383-403. https://doi.org/10.1093/ptj/82.4.383

[16] Sueki, D.G., Cleland, J.A. and Wainner, R.S. (2013) A Regional Interdependence Model of Musculoskeletal Dysfunction: Research, Mechanisms, and Clinical Implications. Journal of Manual \& Manipulative Therapy, 21, 90-102. https://doi.org/10.1179/2042618612Y.0000000027

[17] Hoppenfeld, S. (2019) Physical Examination of the Spine and Extremities. Pearson College, Victoria, 288 Pages.

[18] Robert Cooperstein, M.A. and Lucente, M. (2017) Comparison of Supine and Prone Methods of Leg Length Inequality Assessment. Journal of Chiropractic Medicine, 16, 103-110. https://doi.org/10.1016/j.jcm.2017.01.001

[19] Redmond, A.C., Crosbie, J. and Ouvrier, R.A. (2006) Development and Validation of a Novel Rating System for Scoring Standing Foot Posture: The Foot Posture Index. Clinical Biomechanics, 21, 89-98.

https://doi.org/10.1016/j.clinbiomech.2005.08.002

[20] Gross, M.T., Burns, C.B., Chapman, S.W., et al. (1998) Reliability and Validity of Rigid Lift and Pelvic Leveling Device Method in Assessing Functional Leg Length Inequality. Journal of Orthopaedic \& Sports Physical Therapyapy, 27, 285-294. https://doi.org/10.2519/jospt.1998.27.4.285

[21] Hinson, R. and Brown, S. (1998) Supine Leg Length Differential Estimation: An Inter- and Intra-Examiner Reliability Study. Chiropractic Research Journal, 5, 17-22.

[22] Havran, M., et al. (2016) Deconstructing Chronic Low Back Pain in the Older Adult, Step-By-Step Evidence and Expert-Based Recommendations for Evaluation and Treatment: Part XII: Leg Length Discrepancy. Pain Medicine, 17, 2230-2237. https://doi.org/10.1093/pm/pnw270

[23] Ali, A., et al. (2014) The Importance of Submalleolar Deformity in Determining Leg Length Discrepancy. The Surgeon, 12, 201-205.

https://doi.org/10.1016/j.surge.2013.12.003

[24] Rothbart, B.A., et al. (2006) Relationship of Functional Leg-Length Discrepancy to Abnormal Pronation. Journal of the American Podiatric Medical Association, 96, 507-507. https://doi.org/10.7547/0960507

[25] Sheha, E.D., et al. (2018) Leg-Length Discrepancy, Functional Scoliosis, and Low Back Pain. JBJS Reviews, 6, e6. https://doi.org/10.2106/JBJS.RVW.17.00148

[26] Rannisto, S., et al. (2015) Leg-Length Discrepancy Is Associated With Low Back Pain among Those Who Must Stand While Working. BMC Musculoskeletal Disorders, 16, Article No. 110. https://doi.org/10.1186/s12891-015-0571-9

[27] Raczkowski, J.W., et al. (2010) Functional Scoliosis Caused by Leg Length Discrepancy. Archives of Medical Science, 6, 393-398. https://doi.org/10.5114/aoms.2010.14262

[28] Gross, R.H., et al. (1983) Leg Length Discrepancy in Marathon Runners. The American Journal of Sports Medicine, 11, 121-124. https://doi.org/10.1177/036354658301100303

[29] Cleveland, R.H., et al. (1998) Determination of Leg Length Discrepance. A Comparison of Weight-Bearing and Supine Imaging. Investigative Radiology, 23, 
301-304. https://doi.org/10.1097/00004424-198804000-00010

[30] Hoikka V. et al., (1989) Leg-Length Inequality Has Poor Correlation With Lumbar Scoliosis. Archives of Orthopaedic and Trauma Surgery, 108, 173-175.

https://doi.org/10.1007/BF00934262

[31] Rhodes, D.W., et al. (1995) The Validity of the Prone Leg Check as An Estimate of Standing Leg Length Inequality Measured by X-Ray. Journal of Manipulative and Physiological Therapeutics, 18, 343-346.

[32] Soukka, A., et al. (1991) Leg-Length Inequality in People of Working Age. The Association between Mild Inequality and Low-Back Pain Is Questionable. Spine, 16, 429-431. https://doi.org/10.1097/00007632-199104000-00007

[33] Mincer, A.E., Cummings, G.S, Andrew, P.D. and Rau, J.L. (1997) Effect of Leg Length Discrepancy on Trunk Muscle Fatigue and Unintended Trunk Movement. Journal of Physical Therapy Science, 9, 1-6. https://doi.org/10.1589/jpts.9.1

[34] Sabharwal, S., et al. (2008) Methods for Assessing Leg Length Discrepancy, Clinical Orthopaedics and Related Research, 466, 2910-2922.

https://doi.org/10.1007/s11999-008-0524-9

[35] Gross, M.T., et al. (2015) Lower Quarter Screening for Skeletal Malalignment-Suggestions for Orthotics and Shoewear. Journal of Orthopaedic \& Sports Physical Therapy, 21, 389-405. https://doi.org/10.2519/jospt.1995.21.6.389 